\title{
Accuracy of Cone Beam Computed Tomography in the Assessment of Mandibular Molar Furcation Defects
}

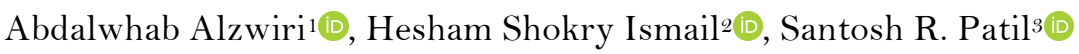

${ }^{1}$ School of Dental Sciences, Universiti Sains Malaysia, Kelantan, Malaysia.

${ }^{2}$ Oral Medicine and Periodontology Department, Faculty of Dentistry, Suez Canal University, Ismailia, Egypt.

${ }^{3}$ Department of Oral Medicine and Radiology, College of Dentistry, Jouf University, Sakaka, Aljouf, Saudi Arabia.

Author to whom correspondence should be addressed: Dr. Santosh R. Patil, Department of Oral Medicine and Radiology, College of Dentistry, Jouf University, Sakaka, Aljouf, Saudi Arabia. Phone: +91 9113075740. E-mail: drpsantosh@gmail.com.

Academic Editors: Alessandro Leite Cavalcanti and Wilton Wilney Nascimento Padilha

Received: 24 April 2019 / Accepted: 13 November 2019 / Published: 27 November 2019

How to cite this article: Alzwiri A, Ismail HS, Patil SR. Accuracy of cone beam computed tomography in the assessment of mandibular molar furcation defects. Pesqui Bras Odontopediatria Clín Integr. 2020; $20: e 4853$. https://doi.org/10.1590/pboci.2020.022

\begin{abstract}
Objective: To evaluate the accuracy of cone-beam computed tomography (CBCT) in the assessment of mandibular molar furcation defects. Material and Methods: Thirty patients with furcation defects were selected, oral hygiene instructions, scaling, and root planing with ultrasonic devices and hand instruments and occlusal adjustments were performed. Pre-surgical clinical measurements were carried out at the buccal aspect of the selected mandibular molars. The horizontal furcation measurements were measured with a Nabers Probe starting at the furcation entrance to the greatest horizontal depth. The degree of furcation involvement was graded from 0 to III. Bone loss in the horizontal and vertical direction and the width of the furcation entrance were measured on CBCT and after reflecting the full-thickness flap and debridement of the defects. The data were analyzed using t-test and Pearson's correlation coefficient. Results: The width of furcation entrance in clinical method was $3.27 \pm 0.77$, while in CBCT method was $3.35 \pm 0.71$, clinically the vertical bone loss was $3.61 \pm 1.09$, while in CBCT was $3.57 \pm 1.15$, horizontal bone loss in clinical method was $5.08 \pm 2.21$, while in CBCT was $5.11 \pm 2.23$. No significant difference between the two methods was noted, and a high correlation between the two methods was observed. With regards to the agreement between the two methods of assessment, the width of furcation entrance revealed a difference between the two methods by $0.08 \pm 0.21$, while vertical bone loss showed difference between the two methods by $-0.04 \pm$ 0.19 , the horizontal bone loss showed a mean difference between the two methods by $0.03 \pm 0.21$. Conclusion: CBCT provided high accuracy for the furcation involvement detection and anatomy of surrounding periodontal tissues.
\end{abstract}

Keywords: Cone-Beam Computed Tomography; Furcation Defects; Molar. 


\section{Introduction}

Periodontal diseases are among the most common conditions affecting humans [1]. The extension of periodontal disease into the bi- or trifurcation of multi-rooted teeth is known as furcation involvement (FI). Periodontists commonly find a great challenge in assessing and treating furcations affected by periodontal disease. Complex anatomy and morphology of the molars pose difficulty for the effective and thorough instrumentation of the furcation defects [2].

The precise diagnosis of periodontal disease affecting a furcation requires the evaluation of the patient's clinical history, periodontal and radiographic examination and, if necessary, laboratory tests. The condition of a furcation must be known before a prognosis can be established [3].

The extent of furcation disease can be determined by evaluating the vertical bone loss and horizontal bone loss [4]. Traditionally, the gold standard diagnosis of furcation involvement is based on clinical examination with a Nabers probe and the periapical radiography (PR). PR is a 2-dimensional imaging technique and might not be accurate enough for the assessment of furcation involvement, mainly as a result of image overlay and a consequent lack of sufficient information [5]. To overcome the inherent difficulties of PR, advanced 3-D image analysis imaging systems has been introduced and are widely used in dentistry [6-12].

Cone-beam computed tomography (CBCT) allows the clinicians to visualize all of the required parameters easily in all dental fields. The utilization CBCT seems to improve the diagnosis and the management in the conventional periodontal treatment and surgeries for the treatment of furcation involved; however, more clinical studies are needed to support this conclusion [13-18]. Therefore, the current study is designed to evaluate the accuracy of CBCT in the assessment of mandibular molar furcation defects.

\section{Material and Methods}

Design

This prospective comparative study was conducted on thirty patients with furcation defects selected from patients presenting to the outpatient clinic at the Department of Periodontology, Oral Diagnosis and Oral Radiology, Faculty of Dentistry, Jouf University. Patients received a CBCT examination to measure their mandibular molar furcation defect, and the measurements were compared with clinical intra-surgical readings taken during the surgical treatment.

\section{Setting and Participants}

The following inclusion criteria were established: Patients with periodontal disease with one or more advanced furcation defects, defined as horizontal inter-radicular loss of periodontal tissues of degree II or III [7]; Patients age range between 30-60 years; and Patients indicated for the surgical approach for the treatment of the furcation defect. Exclusion criteria were: Pregnant females; Patients with furcation caries; Silver amalgam fillings near the alveolar crest; and Metal crowns in the CBCT irradiation area.

\section{Patient Preparation and Data collection}

Initial therapy, including oral hygiene instructions, scaling and root planing with ultrasonic devices and hand instruments and occlusal adjustments, were performed.

Evaluation of the Furcation Defect

Pre-surgical Clinical Measurements 
It was measured at the buccal aspect of the selected mandibular molars. The horizontal furcation measurements were measured with a Nabers Probe (Hu-Friedy, Chicago, USA) starting at the furcation entrance to the greatest horizontal depth. The degree of FI was graded, according to Hamp et al. classification system [19]: • Grade 0: no horizontal loss of periodontal tissue support, i.e., no radiolucency in the furcation area; - Grade I: being up to one-third of the width of the tooth; • Grade II: more than one-third but not encompassing the total width of the tooth; - Grade III: being a through-and-through destruction of the periodontal support.

\section{Measurements of CBCT}

Prior to surgery, CBCT was performed in the posterior mandibular area using the high-resolution imaging system 3D (J. Morita Corp., Kyoto, Japan). Measurements were made to the nearest $0.01 \mathrm{~mm}$ using the On-Demand 3D Software (Cybermed Inc., Seoul, South Korea) with a linear measurement tool and a digital magnification lens.

1. Furcation involvement was calculated in the horizontal plane by measuring to the nearest millimeter, the distance between the outer root surface and the inter-radicular bone (bone loss in the horizontal direction - 'BL-H'). The degree of FI was graded, according to Hamp et al. classification system [19].

2. The degree of bone loss in the vertical direction (BL-V) was decided by measuring the distance from the furcation entrance to the base of the defect in the vertical direction.

3. The width of the furcation entrance $(\mathrm{FW})$ was measured by measuring the greatest mesiodistal distance in the furcation.

\section{Intra-Surgical Measurements}

After administering the local anesthesia, full-thickness flaps were reflected, defects were debrided, and all direct surgical measurements were made.

1. Furcation width (FW) from the buccal aspect of furcation was a measure of the greatest mesiodistal distance in the furcation.

2. The degree of BL-V in the furcation was decided by measuring the distance from the furcation entrance to the base of the defect in the vertical direction.

3. FI was classified according to horizontal measurements [19]. Representing the distance between the outer root surface and the inter-radicular bone (bone loss in the horizontal direction - 'BL-H').

4. Hard tissue measurements rounded up to the nearest $1 \mathrm{~mm}$ were taken for each defect using a curved graduated Nabers probe (HU-Friedy, Chicago, USA), marked at $3 \mathrm{~mm}$ intervals, and a manual $9 \mathrm{~mm}$ periodontal probe (HU-Friedy, Michigan probe, Chicago, USA).

\section{Data Analysis}

The Data was analyzed using Statistical Package for Social Sciences (SPSS, version 21) software. The arithmetic mean, standard deviation, for numerical data t-test was used to compare two groups. To find the association between the two methods of measurements, Pearson's correlation coefficient was used. The level of significance was set at 0.05 .

Ethical Aspects

Ethical clearance was obtained from the Institutional Ethical Committee of College of Dentistry, Jouf University. All patients were informed of the study purpose, and consent was obtained from them. 


\section{Results}

Table 1 shows the comparison between the clinical and CBCT method and its correlations, regarding width of furcation entrance $(\mathrm{FW})$ in clinical method was $3.27 \pm 0.77$, while in CBCT method was $3.35 \pm 0.71$, no significant difference between the two methods was noted, the correlation coefficient between the two methods was 0.82 , i.e., there was a high correlation between the two methods. Vertical bone loss (BL-V) in clinical method was $3.61 \pm 1.09$, while in the CBCT method was $3.57 \pm 1.15$, no significant difference between the two methods was observed, the correlation coefficient between the two methods was 0.911, i.e., there was a high correlation between the two methods. Horizontal bone loss (BL-H) in clinical method was 5.08 \pm 2.21 , while in the CBCT method was $5.11 \pm 2.23$, with no significant difference between the two methods, the correlation coefficient between the two methods was 0.89 , i.e., there was a high correlation between the two methods.

Table 1. Comparison between the clinical and CBCT method and its correlations.

\begin{tabular}{|c|c|c|c|c|}
\hline \multirow[t]{2}{*}{ Variables } & \multicolumn{2}{|c|}{ Method of Assessment } & \multirow{2}{*}{ p-value } & \multirow{2}{*}{$\begin{array}{c}\text { Pearson's } \\
\text { Correlation }(r)\end{array}$} \\
\hline & Clinical & CBCT & & \\
\hline \multicolumn{5}{|c|}{ Width of Furcation Entrance (FW) } \\
\hline Range & $2.0-5.0$ & $2.4-5.0$ & 0.339 & 0.82 \\
\hline Mean (SD) & $3.27 \pm 0.77$ & $3.35 \pm 0.71$ & & \\
\hline \multicolumn{5}{|l|}{ Vertical Bone Loss (BL-V) } \\
\hline Range & $2.0-6.0$ & $2.0-5.7$ & 0.450 & 0.911 \\
\hline Mean (SD) & $3.61 \pm 1.09$ & $3.57 \pm 1.15$ & & \\
\hline \multicolumn{5}{|c|}{ Horizontal Bone Loss (BL-H) } \\
\hline Range & $2.0-8.9$ & $1.8-8.8$ & 0.479 & 0.89 \\
\hline Mean $(\mathrm{SD})$ & $5.08 \pm 2.21$ & $5.11 \pm 2.23$ & & \\
\hline
\end{tabular}

Table 2 shows the agreement between the two methods of assessment, Mean difference (clinical$\mathrm{CBCT}$ ) and $95 \%$ limits of agreement. Width of furcation entrance (FW), show difference between the two methods by $0.08 \pm 0.21$, while Vertical bone loss (BL-V) show difference between the two methods by $-0.04 \pm$ 0.19, the Horizontal bone loss (BL-H), show a mean difference between the two methods by $0.03 \pm 0.21$, the three mean difference can be neglected.

Table 2. Agreement between the two methods of assessment.

\begin{tabular}{|c|c|c|c|c|c|c|}
\hline Variables & $\begin{array}{c}\text { Under } \\
\text { Estimation } \\
(\%)\end{array}$ & $\begin{array}{c}\text { Absolute } \\
\text { Agreement } \\
(\text { diff }=0)(\%)\end{array}$ & $\begin{array}{c}\text { Over } \\
\text { Estimation } \\
(\%)\end{array}$ & $\begin{array}{l}\text { Difference } \\
\text { Mean (SD) }\end{array}$ & $\begin{array}{c}\text { Lower } \\
\text { 95\% Limit }\end{array}$ & $\begin{array}{c}\text { Upper } \\
\text { 95\% Limit }\end{array}$ \\
\hline Width of Furcation Entrance (FW) & 33.3 & 6.7 & 60.0 & $0.08 \pm 0.21$ & -0.30 & 0.52 \\
\hline Vertical Bone Loss (BL-V) & 46.7 & 13.3 & 40.0 & $-0.04 \pm 0.19$ & -0.31 & 0.32 \\
\hline Horizontal Bone Loss (BL-H) & 33.3 & 16.7 & 50.0 & $0.03 \pm 0.21$ & -0.29 & 0.30 \\
\hline
\end{tabular}

\section{Discussion}

The present study has shown that FI assessment by CBCT has shown no significant difference between the intra-surgical and CBCT for all 3 assessed measurements (FW, BL-V, BL-H); thus, CBCT appears to offer a significant advantage over conventional clinical assessments. Furthermore, CBCT provided detailed information about the form of the furcation, the anatomy of the defect, the morphology of the roots and the severity of the lesions that cannot currently be obtained from conventional clinical assessments. 
It has been shown that CBCT provided more detailed information about the degree of FI compared to the clinical findings and periapical radiographs, these results differ from the current study and this may be due to assessment of the defects of the maxillary molars which have different furcation entrance than the mandibular molars [20]. Previous authors concluded that the detected number of the FI was larger by CBCT than clinical examination by means of periodontal probing and suggested that CBCT may be used as an adjunct tool for FI assessment [21].

The accuracy of CBCT in the measurement of horizontal periodontal bone defects was evaluated [22]. The authors measured periodontal bone defects of eight maxillary molars during surgery and compared the results with data taken from $\mathrm{CBCT}$ images. The results showed that $\mathrm{CBCT}$ accurately reproduced the clinical measurement of horizontal periodontal bone defects, which are similar to the current study. It is obvious that the precise detection of the furcation involvement and the evaluation of the root morphology affects the diagnosis and treatment plan and is consequently essential for the tooth prognosis and the maintenance procedures.

\section{Conclusion}

CBCT provided high accuracy for the furcation involvement detection and anatomy of surrounding periodontal tissues. CBCT can thus provide a clear decision about the definitive surgical option.

\section{Authors' Contributions}

\begin{tabular}{|c|c|c|}
\hline AA & (D) $0000-0002-6951-5163$ & $\begin{array}{l}\text { Conceptualization, Methodology, Investigation, Formal Analysis, Writing - } \\
\text { Original Draft Preparation and Writing - Review and Editing. }\end{array}$ \\
\hline HSI & (iD) $0000-0002-0113-3900$ & Conceptualization, Formal Analysis and Writing - Review and Editing. \\
\hline SRP & (iD) $0000-0003-0715-497 \mathrm{X}$ & Methodology, Investigation and Writing - Review and Editing. \\
\hline
\end{tabular}

\section{Financial Support}

None.

\section{Conflict of Interest}

The authors declare no conflicts of interest.

\section{Acknowledgements}

The authors would like to acknowledge the Universiti Sains Malaysia (USM) fellowship awarded to Abdalwhab Zwiri.

\section{References}

[1] Nazir MA. Prevalence of periodontal disease, its association with systemic diseases and prevention. Int J Health Sci 2017; 11(2):72-80.

[2] Masood M, Newton T, Bakri NN, Khalid T, Masood Y. The relationship between oral health and oral health related quality of life among elderly people in United Kingdom. J Dent 2017; 56:78-83. https://doi.org/10.1016/j.jdent.2016.11.002

[3] Avila-Ortiz G, De Buitrago JG, Reddy MS. Periodontal regeneration - furcation defects: a systematic review from the AAP Regeneration Workshop. J Periodontol 2015; 86(2 Suppl):S 108-30. https://doi.org/10.1902/jop.2015.130677

[4] Parihar AS, Katoch V. Furcation involvement \& its treatment: a review. J Adv Med Dent Scie Res 2015; 3(1):81-7.

[5] Salineiro FCS, Gialain IO, Kobayashi-Velasco S, Pannuti CM, Cavalcanti MGP. Detection of furcation involvement using periapical radiography and 2 cone-beam computed tomography imaging protocols with and without a metallic post: an animal study. Imaging Sci Dent 2017; 47(1):17-24. https://doi.org/10.5624/isd.2017.47.1.17 
[6] Cimbaljevic MM, Spin-Neto RR, Miletic VJ, Jankovic SM, Aleksic ZM, Nikolic-Jakoba NS. Clinical and CBCT-based diagnosis of furcation involvement in patients with severe periodontitis. Quintessence Int 2015; 46(10):863-70. https://doi.org/10.3290/j.qi.a34702

[7] Patil SR, Ghani HA, Almuhaiza M, Al-Zoubi IA, Anil KN, Misra N, Raghuram PH. Prevalence of pulp stones in a Saudi Arabian subpopulation: a cone-beam computed tomography study. Saudi Endod J 2018; 8(2):93-8. https://doi.org/10.4103/sej.sej_32_17

[8] Patil SR, Araki K, Ghani HA, Al-Zoubi IA, Sghaireen MG, Gudipaneni RK, et al. A cone beam computed tomography study of the prevalence of pulp stones in a Saudi Arabian adolescent population. Pesqui Bras Odontoped Clin Integr 2018; 18(1):e3973. https://doi.org/10.4034/PBOCI.2018.181.45

[9] Sinha N, Singh B, Patil S. Cone beam computed topographic evaluation of a central incisor with an open apex and a failed root canal treatment using one-step apexification with Biodentine ${ }^{\mathrm{TM}}$ : a case report. J Conserv Dent 2014; 17(3):285-9. https://doi.org/10.4103/0972-0707.131805

[10] Al-Zoubi IA, Patil SR, Takeuchi K, Misra N, Ohno Y, Sugita Y, et al. Analysis of the length and types of root trunk and length of root in human first and second molars and to the actual measurements with the $3 \mathrm{D}$ CBCT. J Hard Tissue Biol 2018; 27(1):39-42. https://doi.org/10.2485/jhtb.27.39

[11] Alam MK, Alhabib S, Alzarea BK, Irshad M, Faruqi S, Sghaireen MG, et al. 3D CBCT morphometric assessment of mental foramen in Arabic population and global comparison: imperative for invasive and non-invasive procedures in mandible. Acta Odontol Scand 2018; 76(2):98-104. https://doi.org/10.1080/00016357.2017.1387813

[12] Patil SR, Alam MK, Moriyama K, Matsuda S, Shoumura M, Osuga N. 3D CBCT assessment of soft tissue calcification. J Hard Tissue Biol 2017; 26(3):297-300. https://doi.org/10.2485/jhtb.26.297

[13] Al-Zoubi IA, Patil SR, Kato I, Sugita Y, Maeda H, MK. 3D CBCT Assessment of incidental maxillary sinus abnormalities in a Saudi Arabian population. J Hard Tissue Biol 2017; 26(4):369-72.

[14] Patil SR, Araki K, Yadav N, Ghani HA. Prevalence of hypercementosis in a Saudi Arabian Population: a cone beam computed tomography study. J Oral Res 2018; 7(3):94-7. https://doi.org/10.17126/joralres.2018.022

[15] Patil SR, Maragathavalli G, Araki K, Al-Zoubi IA, Sghaireen MG, Gudipaneni RK, et al. Three-rooted mandibular first molars in a Saudi Arabian population: A CBCT study. Pesqui Bras Odontopediatria Clin Integr 2018; 18(1):e4133. https://doi.org/10.4034/PBOCI.2018.181.87

[16] Patil SR, Raghuram PH, Munisekhar MS, Shailaja G, Gudipanen Ri, Alam MK. CBCT evaluation of an unusual case of florid cementoosseous dysplasia in an old female. Int Med J 2018; 25(5):335-6.

[17] Alam MK, Ganji KK, Alzarea, Patil S, Sghaireen M, Basri R, et al. 3D CBCT assessment of the mandibular canal in a Saudi Arabian subpopulation. J Hard Tissue Biol 2019; 28(1):87-92. https://doi.org/10.2485/jhtb.28.87

[18] Patil SR. Comparative measurement of tooth length: actual vs. orthopantomography and CBCT-based measurements. Pesqui Bras Odontopediatria Clín Integr 2019; 19(1):e4637. https://doi.org/10.4034/PBOCI.2019.191.38

[19] Hamp SE, Nyman S, Lindhe J. Periodontal treatment of multi rooted teeth. J Clin Periodontol 1975; 2(3):126-35. https://doi.org/10.1111/j.1600-051x.1975.tb01734.x

[20] Walter C, Weiger R, Zitzmann NU. Accuracy of three-dimensional imaging in assessing maxillary molar furcation involvement. J Clin Periodontol 2010; 37(5):436-41. https://doi.org/10.1111/j.1600-051X.2010.01556.x

[21] Cimbaljevic M, Misic J, Jankovic S, Nikolic-Jakoba N. The use of cone-beam computed tomography in furcation defects diagnosis. Balkan J Dent Med 2016; 20(3):143-8. https://doi.org/10.1515/bjdm-2016-0023

[22] Feijo CV, Lucena JG, Kurita LM, Pereira SL. Evaluation of cone beam computed tomography in the detection of horizontal periodontal bone defects: an in vivo study. Int J Periodontics Restorative Dent 2012; 32(5):e162-8. 